\title{
The new ethics of Aboriginal health research
}

$\mathrm{R}$

esearch can be a four-letter word in Aboriginal communities. For centuries, scientists of all stripes have dropped in, taken notes and taken off - sometimes forcibly taking their "subjects" with them. But as indigenous people demand a greater say in the priorities, methods and interpretation of research conducted in their communities, a new paradigm is emerging: partner or perish.

Presenters at the November 2014 Indigenous Health Conference in Toronto argued that research-as-usual is no longer acceptable. "Health research as it happens in our communities is one of the last vestiges of colonialism," said Natan Obed, director of the Department of Social and Cultural Development for Nunavut Tunngavik Inc., which represents beneficiaries of the Nunavut Land Claims Agreement. "Academics from the south and government agencies are in control of how the money flows through our communities and the terms and conditions that investigators use - and we are the ones that allow it to happen."

Nonindigenous investigators still do

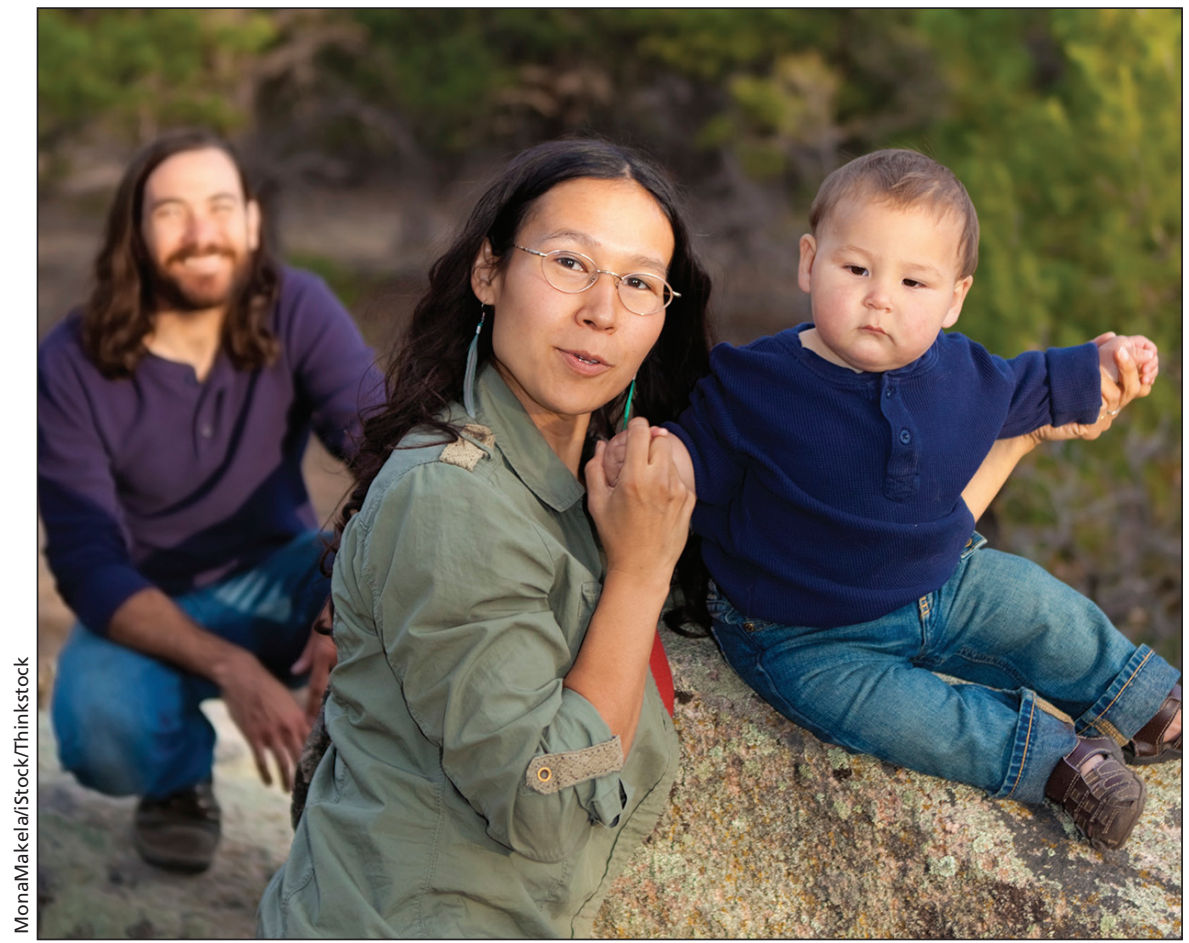

Aboriginal communities are setting news rules of engagement for more personal, collaborative relationships with researchers. the bulk of indigenous health research in Canada. And according to a 2003 study in the $B M J$ much of this research overlooks considerable geographic, cultural, economic and even health differences in the Aboriginal population.

Ethics boards and funding bodies such as the Canadian Institutes of Health Research have attempted to redress these issues in recent years by refining guidelines for working with Aboriginal communities, including parts of the Tri-Council Policy statement on Ethical Conduct for Research Involving Humans in 2014. But despite these efforts, it's often still a case of too little collaboration, too late, said Obed.

"We're forced into positions where we can only comment negatively because we're reacting to something that's already underway," he explained. "True partnerships happen when you come with a blank slate, long before research ethics or funding agencies ask for your list of partners."

\section{Redefining relationships}

Increasingly Aboriginal communities and organizations are pushing back

with their own codes of conduct and ethical criteria for research partnerships. The 2007 First Nations Regional Longitudinal Health Survey code of research ethics is one of the most cited examples. It sets requirements for community ownership, control, access and possession of date. Other documents, including 2009 Assembly of First Nations guidelines also emphasize personal relationship, mutual benefit, and community employment in research.

"Our communities are very aware that the knowledge they provide is currency for researchers in terms of jobs and accolades," says Jo-Ann Episkenew, director of the Indigenous Peoples' Health Research Centre in Regina. "If researchers don't treat them with respect - which means getting to know them, understanding how they define respectful behaviour, and ensuring that everyone benefits - then the communities will say no."

Part of the difficulty in negotiating these partnerships may be that investigators and indigenous people have widely different notions about what "relationship" means in the context of research. "In medicine, relationship building is all about professionalism," says Episkenew. "But if a community doesn't trust you in the first place, being a detached, objective professional isn't going to do much to bridge that gap."

In the Saddle Lake Cree Nation in Alberta, relationship means immersing in community life and traditions, says Dr. James Makokis, a local family physician whose practice combines Western medicine and traditional Cree teachings. "Part of the ethics process in our area is having a pipe ceremony which invokes a third party, the Creator. That's more powerful than going to a research ethics board at an institution which knows nothing about our people and our ways."

\section{Rethinking methods}

Under the new rules of engagement, researchers may also be expected to change the goals and methods of their work to reflect local priorities. This can be challenging, even for indige- 
nous investigators, says Episkenew. She recalls one project grinding to halt when the children involved became fixed on what were meant to be warmup games. Ultimately, the research team changed their study to focus on the games. "We realized they had parents for whom playing with the imagination is a foreign concept because
"You need to take a wide lens approach," explains Makokis. "It's taken hundreds of years for our health disparities to get where they are and it's not going to take a five-year research project for you to start seeing immediate changes."

But that sort of approach can bring financial issues, says Kevin Willison, a

\section{"If researchers don't treat them with respect... then the communities will say no."}

they grew up institutionalized," says Episkenew. "We could have cherry picked the kids that did what we wanted ... but what we actually did was more valuable."

In some cases, however, that value won't be easily or immediately measurable — particularly if Western-style empiricism isn't a community's research method of choice.

"Sometimes there won't be an immediate hard outcome, but that doesn't mean there hasn't been a positive change in the community," says Makokis. He cites the example of building a community garden as part of a sexual health project. "People come out and participate, and it creates a safe space to start engaging around those sensitive issues." member of Public Health Ontario's Ethics Review Board and professor of sociology at Lakehead University in Thunder Bay. Funding for indigenous health research seldom takes into account the extra time needed to design and carry out the kind of collaborative projects that communities are demanding. Meaningful evaluation of a communitybased participatory approach is also difficult given that these projects are, by definition, unique to one community. "We have nothing really to compare it to," says Willison.

Proponents of community-based research acknowledge that it can be slow and messy. However, they say it's worth the effort to generate data that more accurately reflect Aboriginal realities.
In Nova Scotia, for example, a community-driven data linkage project revealed surprising disparities in oral health. Previously, it was impossible to get a clear picture of First Nations health in the province because surveillance was fragmented across various agencies, says Sharon Rudderham, health director at the Eskasoni Community Health Centre, which serves Nova Scotia's largest Mi'kmaq community.

Gathering First Nations data under a single registry governed by the communities revealed that $42 \%$ of ambulatory care admissions were related to dental issues. "We were extremely shocked," says Rudderham. "We knew about the issues with diabetes, obesity and addictions in our communities, but no one knew about this."

Ultimately, though, Rudderham says the process of negotiating better partnerships may be more important for the long-term health of communities than any immediate outcomes. For example, people are more likely to sustain health interventions they helped design. "It goes back to our ability to take ownership and control," she says. "When you and your family have a say, then it has more of an impact." Lauren Vogel, CMAJ

CMAJ 2015. DOI:10.1503/cmaj.109-4998

\section{Red tape blocks care for Aboriginal children}

$\mathrm{E}$ ight years after the House of Commons unanimously approved the principle that no First Nations child should be denied health services because of inter-jurisdictional wrangling over costs, Ottawa is engaging in "structural racism" by narrowing the definition of cases so none qualify, says the principal researcher behind a new report.

"The structure of funding and service delivery for First Nations children is much more complicated than the structure of services for other children," says Vandna Sinha, an assistant professor in the School of Social Work at
McGill University. "I would call that structural racism."

Sinha leads six researchers from McGill, the University of Manitoba and the University of Michigan, whose Feb 10 report examines the implementation of Jordan's Principle, which Parliament approved in 2007. The principle is named for Jordan River Anderson, a five-year-old boy from Norway House Cree Nation in Manitoba. Jordan died in the Winnipeg hospital where he had been confined for two years while the federal and provincial governments argued over who should pay for his home-care costs.
Jordan's principle states that whichever government department or level of government is first contacted about health and welfare services for a First Nations child should supply whatever services would be available to a nonAboriginal child without delay, and iron out jurisdictional responsibility for payment later.

Working with the Assembly of First Nations, the Canadian Association of Paediatric Health Centres, the Canadian Paediatric Society and UNICEF Canada, the researchers launched an investigation into why the federal government and some provincial govern- 